\title{
Effects of caffeic acid on epigenetics in the brain of rats with chronic unpredictable mild stress
}

\author{
JINYE HU*, SHUYUAN CAO* , ZHAN ZHANG, LI WANG, DI WANG, QIAN WU and LEI LI \\ Department of Health Inspection and Quarantine and Ministry of Education Key Lab for Modern Toxicology, \\ School of Public Health, Nanjing Medical University, Nanjing, Jiangsu 211166, P.R. China
}

Received December 16, 2019; Accepted September 11, 2020

DOI: $10.3892 / \mathrm{mmr} .2020 .11609$

\begin{abstract}
The present study hypothesized that caffeic acid (3,4-dihydroxycinnamic acid; CaA) may exert antidepressant-like effects in rats with chronic unpredictable mild stress via epigenetic mechanisms, such as DNA methylation and hydroxymethylation. The chronic unpredictable mild stress (CUMS) model was used to analyze the effects of $\mathrm{CaA}$ on behavioral phenotypes, and to evaluate the distribution of 5-methylcytosine $(5 \mathrm{mC})$ and 5-hydroxymethylcytosine $(5 \mathrm{hmC})$ in the hippocampus and prefrontal cortex using immunohistochemistry and immunofluorescence. mRNA levels of the genes encoding brain-derived neurotropic factor (BDNF) and catechol-O-methyltransferase (COMT), and key enzymes regulating DNA methylation [DNA methyltransferase (DNMT)1 and DNMT3A] and hydroxymethylation [Ten-eleven translocation (TET)1-3] were examined using quantitative (q)PCR. Furthermore, enrichment of $5 \mathrm{mC}$ and $5 \mathrm{hmC}$ at the promotor regions of the $B d n f$ and Comt genes was quantified using chromatin immunoprecipitation-qPCR. Behavioral data showed that CaA exerted a slight antidepressant-like effect. Bdnf and Comt genes showed differential expression patterns due to CUMS. CaA intervention induced different Dnmt1/Dnmt3a and Tet1/Tet 2 mRNA levels in the hippocampus and prefrontal cortex, respectively. $\mathrm{CaA}$ regulated the ratio of $5 \mathrm{mC} / 5 \mathrm{hmC}$ at the promotor region of the Bdnf and Comt genes and therefore influenced gene expression, which may be a valuable therapeutic option for major depressive disorder (MDD). In conclusion, there were epigenetic changes in the hippocampus and prefrontal cortex
\end{abstract}

Correspondence to: Dr Qian Wu or Professor Lei Li, Department of Health Inspection and Quarantine and Ministry of Education Key Lab for Modern Toxicology, School of Public Health, Nanjing Medical University, 101 Longmian Avenue, Nanjing, Jiangsu 211166, P.R. China E-mail:wuqian@njmu.edu.cn

E-mail: 1ilei@njmu.edu.cn

*Contributed equally

Key words: caffeic acid, epigenetics, methylation, hydroxymethylation, depression in CUMS rats, and CaA may function as a modulator of DNA methylation to regulate gene transcription, thus providing a mechanistic basis for the use of this phytochemical agent in the treatment of MDD.

\section{Introduction}

Caffeic acid (3,4-dihydroxycinnamic acid; $\mathrm{CaA})$ is a natural hydroxycinnamic acid that is found in coffee, argan oil and barley grain (1). Studies have shown that $\mathrm{CaA}$ has anticancer, anti-oxidant and anti-inflammatory properties and can be activated both in vitro and in vivo (2-5). In addition, as a dietary catechol, CaA can function as an inhibitor of DNA methylation through the increased formation of S-adenosyl-L-homocysteine via catechol-O-methyltransferase (COMT)-mediated O-methylation (6). COMT has multiple functions in neurological, estrogen-associated and methylation metabolic pathways, such as catecholamine, estradiol and estrone metabolism $(7,8)$. Expression of the COMT gene primarily determines dopaminergic levels in the prefrontal cortex. Therefore, variations in COMT activity and expression may be involved in the pathogenesis of various psychiatric and neurological diseases, including schizophrenia and depression $(9,10)$. A large amount of research has focused on a common, single nucleotide polymorphism of the COMT gene, Val158Met, which results in high activity of the COMT enzyme, contributing to the pathophysiology of major depressive disorder (MDD) (11). Previous studies have suggested that methylation of the COMT gene impacts its subsequent expression $(12,13)$. Our previous study showed that phytochemically-stimulated COMT expression reversed the estrogen-induced inhibition of COMT via epigenetic mechanisms (14).

A recent study indicated that aberrations in epigenetic modification, particularly DNA methylation of 5-methylcytosine $(5 \mathrm{mC})$ in regions that are differentially methylated, are associated with depression (15). DNA methylation is initiated and maintained by DNA methyltransferases (DNMTs), which would be expected to decrease gene expression. Recent studies have shown that $5 \mathrm{mC}$ can be oxidized by members of the ten-eleven translocation (TET) protein family to form 5-hydroxymethylcytosine (5hmC), which could mediate DNA hydromethylation and increase gene expression (16,17). These epigenetic enzymes, including methyl CpG binding proteins, DNMTs and TETs, can bind to DNA and thus regulate gene expression. It has been reported that alteration 
in the expression of neurogenesis-associated genes via methylation regulation is associated with depression in a rat model (18).

Brain-derived neurotrophic factor (BDNF) is a member of the neurotrophin family of growth factors. Previous research has shown that expression of $B d n f$ was decreased in psychiatric disorders, such as depression (19), ultimately leading to atrophy of the hippocampus. $B d n f$ transcription is controlled by eight promotors, leading to different mRNAs containing one of the eight untranslated 5'-exons (I to VIII) and the 3 ' encoding exon (IX) (20). The promotor IV region contains a cAMP responsive element as the key regulatory component (21), the expression of which is a good indicator of total $B d n f$ expression in the brain (22). The $B d n f$ promotor IV is also epigenetically regulated, through both DNA methylation and hydroxymethylation (23).

In the present study, it was hypothesized that $\mathrm{CaA}$ could influence gene-specific methylation status in the brain of a rat model with chronic unpredictable mild stress (CUMS), potentially mediated by the epigenetic effects of $\mathrm{CaA}$ on the transcription of Dnmt and/or Tet genes. Therefore, the aim of the present study was to investigate antidepressant-like activity via the epigenetic mechanisms of $\mathrm{CaA}$ focusing on the hippocampus and prefrontal cortex using a well-established model of CUMS $(24,25)$.

\section{Materials and methods}

Animals. A total of 40 male Wistar rats (age, 4 weeks; mean weight \pm SD, $100 \pm 10 \mathrm{~g}$ ), were purchased from Shanghai SLAC Laboratory Animal Co., Ltd. The size of cages was 460x300x160 mm and animal designs were set up as previously described (26) (Table SI; Appendices S1 and S2). Briefly, after 2 weeks of acclimatization the rats were first trained over a period of 3 weeks to consume a $1 \%$ sucrose solution. Then, the rats were randomly and equally divided into four groups: A control group, a CUMS model group, a model group treated with the antidepressant paroxetine (Sigma-Aldrich; Merck KGaA), and a model group treated with CaA (Sigma-Aldrich; Merck KGaA). Paroxetine and $\mathrm{CaA}$ were administered intraperitoneally at doses of 10and $50 \mathrm{mg} / \mathrm{kg}$ for at 9:00 a.m. every day for 4 weeks, respectively. Rats in the control (no treatment) and treated groups were exposed to a series of CUMS and behavioral tests, including the sucrose preference test (SPT) and the forced swimming test (FST) (26). During these tests, food consumption and body weight were evaluated as an indicator of depression as previously described (26) (data not shown). The present study was approved by The Nanjing Medical University Institutional Animal Care and Use Committee (Nanjing, China).

Sample collection and preparation. After 4 weeks, $300 \mathrm{mg} / \mathrm{kg} 10 \%$ chloral hydrate solution per rat was injected intraperitoneally. No rats exhibited signs of peritonitis following administration of the anesthetic, and rats were euthanized by dislocation of the cervical vertebrae. The heart was exposed and heartbeat was assessed to confirm death. No mortality occurred outside of planned euthanasia. The hippocampus and the prefrontal cortex were dissected from the brain of sacrificed animals by a trained expert technician on ice, fixed with $4 \%$ formaldehyde overnight at room temperature, and were subsequently paraffin-embedded, or frozen with liquid nitrogen and stored at $-80^{\circ} \mathrm{C}$ for subsequent experiments.
Immunofluorescence (IF) and immunohistochemistry (IHC) analyses. After paraffin embedding, 3- $\mu \mathrm{m}$ thick sections were obtained, dewaxed and washed in water. Then, sections were immersed in xylene and dehydrated in graded concentrations of absolute ethanol $(95,85,75$ and $50 \%)$ at room temperature. For IHC $(5 \mathrm{mC})$ and IF $(5 \mathrm{hmC})$, sections were blocked for $30 \mathrm{~min}$ at room temperature with 5\% BSA (Beyotime Institute of Biotechnology) and incubated overnight at $4^{\circ} \mathrm{C}$ with anti-5mc (1:200; cat. no. 28692; Cell Signaling Technology, Inc.) and anti-5hmC (1:200; cat. no. 39770; Active Motif, Inc.) antibodies, respectively. Afterwards, sections were washed three times with PBS and incubated for a further $1 \mathrm{~h}$ at room temperature with horseradish peroxidase-labeled goat anti-rabbit antibody $(1: 1,000$; cat. no. GB23303; Wuhan Servicebio Technology Co., Ltd.) in blocking buffer (Beyotime Institute of Biotechnology). For IHC, nuclei were stained with Harris hematoxylin for $2 \mathrm{~min}$ at room temperature. Staining intensity for IHC was digitalized with Panoramic SCAN (3DHISTECH Ltd.) (light microscopy mode). Each immunohistochemically stained slide was scanned with a 20x objective and images were captured at x10 magnification. For further evaluation of IHC imaging, $5 \mathrm{hmC}$ level was quantified by integrated optical density (IOD) of positive brown staining using Image-Pro Plus version 6.0 software (Media Cybernetics, Inc.).

For IF, an Alexa-488 labeled secondary antibody (1:300; cat. no. GB25301; Wuhan Servicebio Technology Co., Ltd.) in blocking buffer (Beyotime Institute of Biotechnology) was used for $2 \mathrm{~h}$ at $4^{\circ} \mathrm{C}$, and nuclei were stained with DAPI at room temperature for $1 \mathrm{~h}$. Images for IF were captured using a Zeiss LSM 700B confocal microscope and the magnification was $\mathrm{x} 400$. The proportion (\%) of $5 \mathrm{hmC}$-positive foci was then quantified and calculated by the positive (green) fluorescent intensity normalized by positive staining area using Image-Pro Plus version 6.0 software (Media Cybernetics, Inc.). All IF experiments were performed in at least three independent biological replicates.

Quantification of mRNA levels of epigenetic modulators and specific genes using reverse transcription-quantitative (RT-q) $P C R$. Total RNA was extracted using the FastPure Cell/Tissue Total RNA Isolation kit (Vazyme Biotech Co., Ltd.) and reverse transcribed into cDNA using the PrimeScript ${ }^{\mathrm{TM}}$ RT reagent kit (Takara Biotechnology Co., Ltd.) following the manufacturer's instructions. mRNA levels of Dnmt1, Dnmt3a, Tet1-3, methyl CpG binding protein 2 (Mecp2), Bdnf and Comt genes were quantified using SYBR Green-based qPCR using 2X SYBR Green PCR mix (Takara Biotechnology Co., Ltd.) according to the manufacturer's instructions. Primer sequences are listed in Table I $(15,19,26)$. All amplifications were performed in triplicate using a LightCycler ${ }^{\circledR} 96$ (Roche Diagnostics) according to the manufacturer's instructions with the following cycle parameters: $95^{\circ} \mathrm{C}$ for $600 \mathrm{sec}$, followed by 45 repeats of $95^{\circ} \mathrm{C}$ for $15 \mathrm{sec}$ and $60^{\circ} \mathrm{C}$ for $60 \mathrm{sec}$. The $2^{-\Delta \Delta \mathrm{Cq}}$ method was used to calculate the relative expression level of the transcripts normalized to levels of GAPDH (27).

Specific promotor methylation and hydroxymethylation analysis. Chromatin immunoprecipitation was performed using the chromatin immunoprecipitation (ChIP)-IT Express kit (Active Motif, Inc.) according to the manufacturer's instructions. A total of $20-30 \mathrm{mg}$ tissues were fixed with 
Table I. Primers for quantitative PCR.

\begin{tabular}{|c|c|}
\hline Gene & Primer sequence, $5^{\prime} \rightarrow 3^{\prime}$ \\
\hline \multicolumn{2}{|l|}{ Tetl } \\
\hline Forward & CCGGTCGCCAAGTGGGTGAT \\
\hline Reverse & GGTCCACACGCTCACGAACCA \\
\hline \multicolumn{2}{|l|}{ Tet2 } \\
\hline Forward & TACCGTACAGCCACCCAAAC \\
\hline Reverse & CGT GACTGGAACTGCTCACT \\
\hline \multicolumn{2}{|l|}{ Tet3 } \\
\hline Forward & GGACTTCTGTGCCCACGCCC \\
\hline Reverse & TCAGGGTGCAGACCACAGTGC \\
\hline \multicolumn{2}{|l|}{ Dnmt1 } \\
\hline Forward & GGCCAGCCCCATGAAACGCT \\
\hline Reverse & GGGGCGTCCAGGTTGCTTCC \\
\hline \multicolumn{2}{|l|}{ Dnmt3a } \\
\hline Forward & TCCAACATGAGCCGCTTGGCG \\
\hline Reverse & GGTGGCGGATGACTGGCACG \\
\hline \multicolumn{2}{|l|}{ Mecp2 } \\
\hline Forward & CTTGACCTCAATGCTGACGGT \\
\hline Reverse & GGGTAGAAAGCCTGGGAGTGT \\
\hline \multicolumn{2}{|l|}{$B d n f P 4$} \\
\hline Forward & GCTGCCTTGATGTTTACTTTGA \\
\hline Reverse & GCAACCGAAGTATGAAATAACC \\
\hline \multicolumn{2}{|l|}{ Total Bdnf } \\
\hline Forward & GGCCCAACGAAGAAAACCAT \\
\hline Reverse & AGCATCACCCGGGAAGTGT \\
\hline \multicolumn{2}{|l|}{ Comt } \\
\hline Forward & TCCACAACCTGATCATGGGT \\
\hline Reverse & ACATCGTACTTCTTCTTCAGCTGG \\
\hline \multicolumn{2}{|l|}{$G A P D H$} \\
\hline Forward & TCGGTGTGAACGGATTTGGCCG \\
\hline Reverse & CCGTTGAACTTGCCGTGGGT \\
\hline
\end{tabular}

Tet, Ten-eleven translocation; Dnmt, DNA methyltransferase; Mecp, methyl $\mathrm{CpG}$ binding protein; brain-derived neurotropic factor; $B d n f$, brain-derived neurotropic factor; $\mathrm{P} 4$, promotor IV region; Comt, catechol-O-methyltransferase.

$1 \%$ formaldehyde at room temperature for $15 \mathrm{~min}$ and lysed with lysis buffer in ChIP-IT Express kit (Active Motif, Inc.) to release chromatin. Chromatin was then enzymatically sheared to obtain chromatin, 100-500 base pairs (bp) in length, using an Enzymatic Shearing kit (Active Motif, Inc.). Approximately $50 \mathrm{ng}$ sheared chromatin was then immunoprecipitated with antibodies against $5 \mathrm{mc}(1: 200$; cat. no. 61479) and $5 \mathrm{hmc}(1: 200$; cat. no. 39769) (both from Active Motif, Inc.) overnight at $4^{\circ} \mathrm{C}$. Immunoglobulin $\mathrm{G}$ was used as a mock control. DNA released from the reverse crosslink was purified (Universal DNA Purification kit; cat. no. DP214-02; Tiangen Biotech Co., Ltd.) according to the manufacturer's instructions. Native chromatin was used as an initial input sample. The level of DNA bound to $5 \mathrm{mC}$ and $5 \mathrm{hmC}$ antibodies was quantified using SYBR-green based qPCR. Primers were designed to amplify regions of
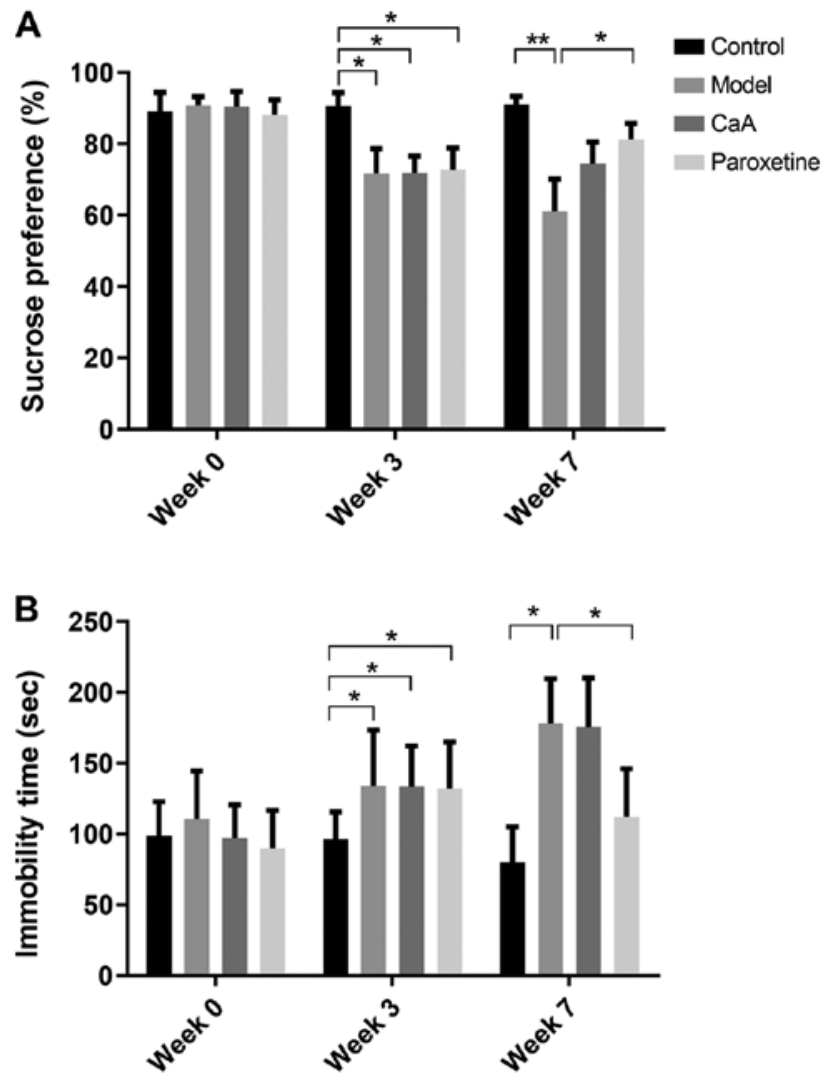

Figure 1. Results of behavioral tests for (A) sucrose preference test and (B) forced swim test for the control, model, CaA and paroxetine treatment groups. ${ }^{*} \mathrm{P}<0.05,{ }^{* *} \mathrm{P}<0.01$. CaA, caffeic acid.

$B d n f$ and Comt promotor as follows: ChIP-Bdnf, forward: 5'-TTGTGGCATGGTTCTCAACC-3' and reverse: 5'-TAGAT CTCTGAGAAGAGGTA-3'; and ChIP-Comt, forward: 5'-TTT GGAGCAGGAGTAGACC-3' and reverse: 5'-TTTTAACACG CGCGGGACG-3'. PCR conditions were programmed as follows: $95^{\circ} \mathrm{C}$ for $20 \mathrm{sec}$, followed by 40 cycles $95^{\circ} \mathrm{C}$ for $3 \mathrm{sec}$ and $60^{\circ} \mathrm{C}$ for $30 \mathrm{sec}$. The levels of bound DNA sequences were then calculated using the percent input method (2- $2^{-\mathrm{Cq}(\mathrm{ChIP})}$ $\left.-\mathrm{Ct}(\mathrm{Input}) \mathrm{x} \times{ }^{100}\right)(14)$ by calculating the qPCR signal relative to the input sample.

Statistical analysis. All data are presented as the mean \pm standard deviation. For group comparisons, Kruskal-Wallis tests were used followed by Dunn's post hoc test. All data were analyzed and plotted with GraphPad Prism version 6.0 (GraphPad Software). $\mathrm{P}<0.05$ was considered to indicate a statistically significant difference.

\section{Results}

CaA can reverse changes in the behavior test induced by the CUMS procedure. The SP of each rat in the control group decreased in the first three CUMS procedures. Over the next 4 weeks of the CUMS procedure, the SP of the model group was continually decreased compared with that of the control group. Furthermore, SP was reversed by $\mathrm{CaA}$ and paroxetine treatment. During week 3, the model group, $\mathrm{CaA}$ and paroxetine groups were significantly decreased compared with the control $(\mathrm{P}<0.05)$. However, only paroxetine treatment showed 
A Hippocampus
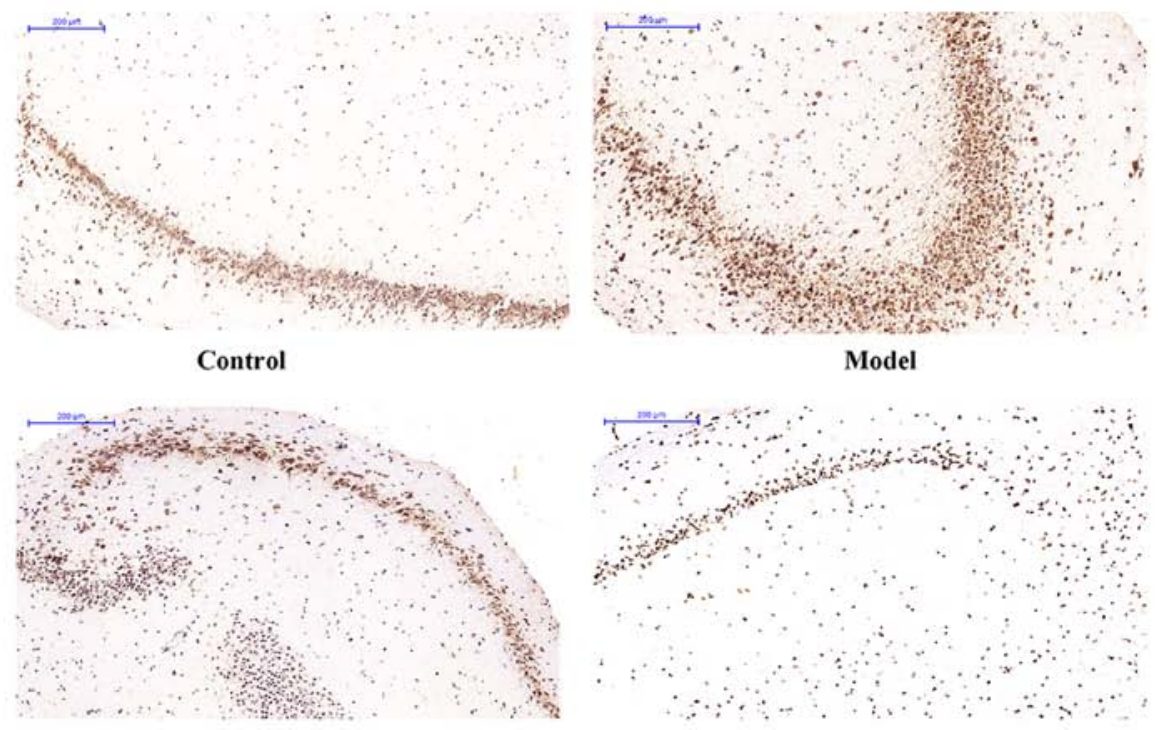

$\mathrm{CaA}$

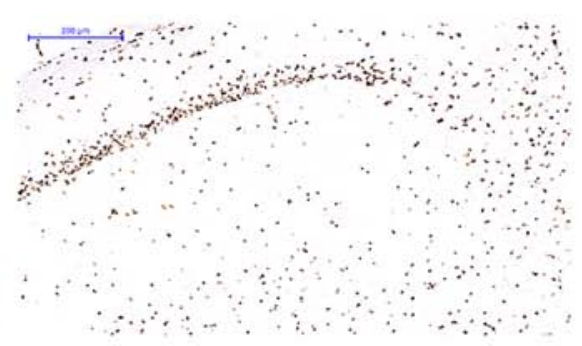

Paroxetine

B Prefrontal cortex
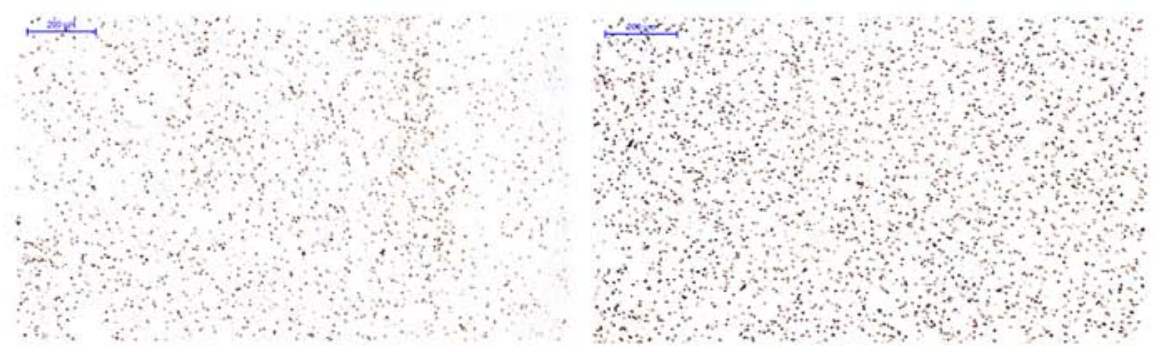

Control

Model

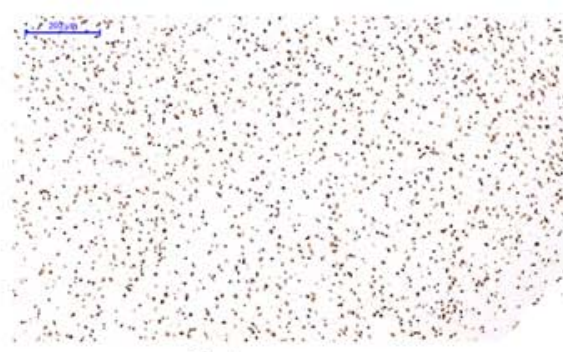

$\mathrm{CaA}$

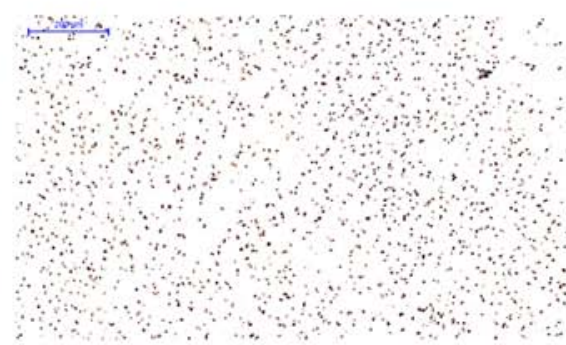

Paroxetine

Figure 2. Immunohistochemistry staining of 5-methylcytosine in the (A) hippocampus and (B) prefrontal cortex of the control, model, CaA and paroxetine treatment groups. Scale bar, $200 \mu \mathrm{m}$. CaA, caffeic acid.

statistical significance when compared with the model group during week 7 ( $\mathrm{P}<0.05$; Fig. 1A). Immobility time in the FST (26) was clearly increased in the model group during the CUMS procedure. In the model group, $\mathrm{CaA}$ and paroxetine treatment were significantly increased compared with the control during week 3 . However, paroxetine treatment caused a significant decrease in immobility time compared with the model group and $\mathrm{CaA}$ treatment had no significant effect on FST during week 7 ( $\mathrm{P}<0.05$; Fig. 1B).

Comparison of global $5 \mathrm{mC}$ and $5 \mathrm{hmC}$ in the hippocampus and prefrontal cortex. The levels of global $5 \mathrm{mC}$ (IHC) and global $5 \mathrm{hmC}$ (IF) in the hippocampus and prefrontal cortex were detected, respectively. Immunostaining of $5 \mathrm{mC}$ was localized

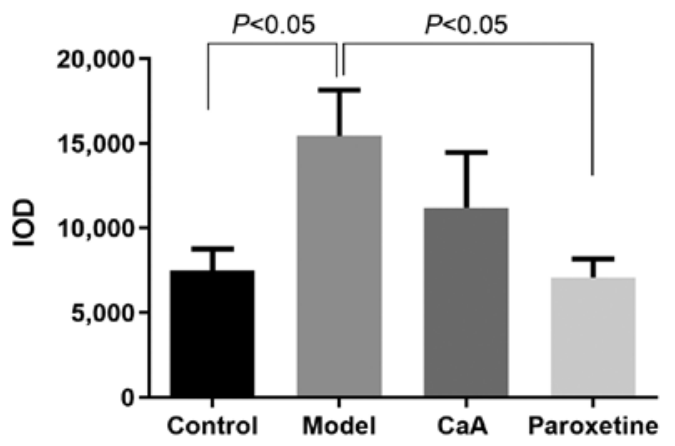

Figure 3. IOD for immunohistochemistry image analysis in the hippocampus. The same density of dark brown was selected from all images as standards using Image-Pro Plus 6.0 software. IOD, integrated optical density; $\mathrm{CaA}$, caffeic acid. 
A Hippocampus

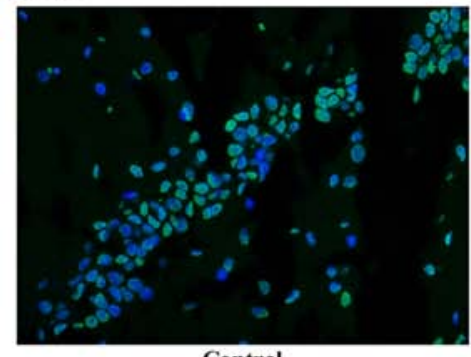

Control

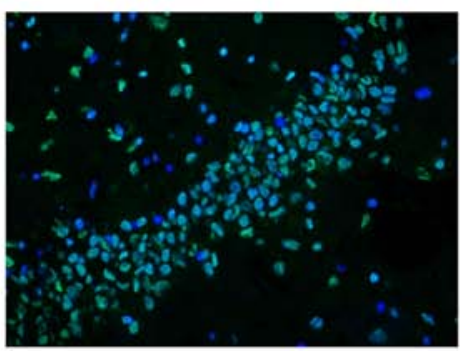

CaA

B Prefrontal cortex

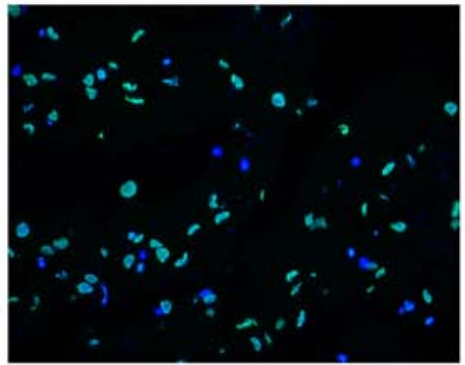

Control

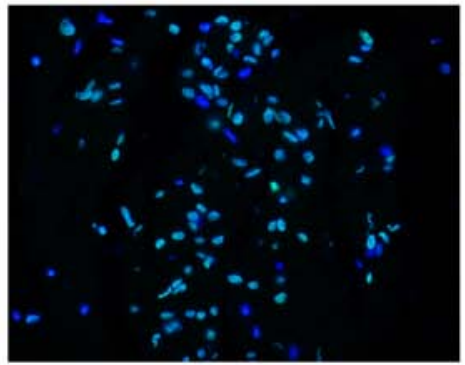

$\mathrm{CaA}$

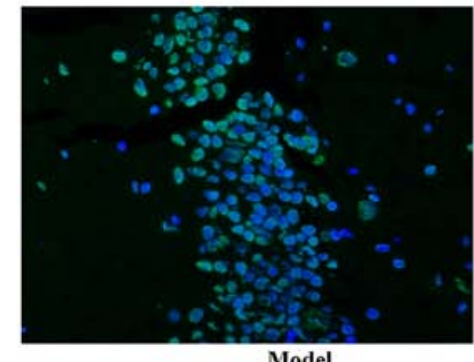

Model

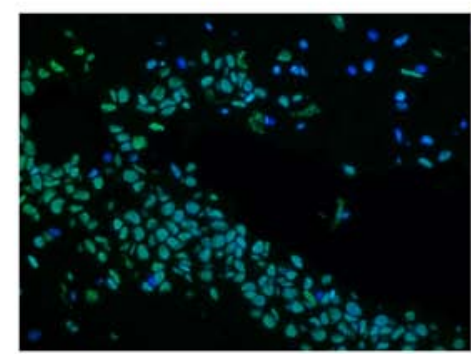

Paroxetine

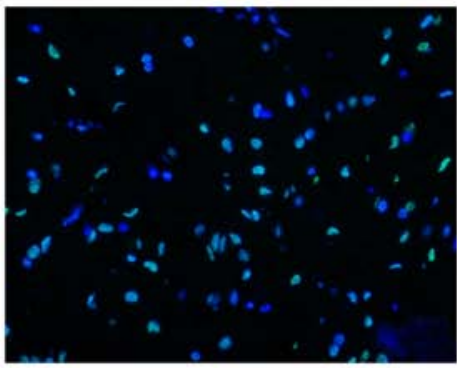

Model

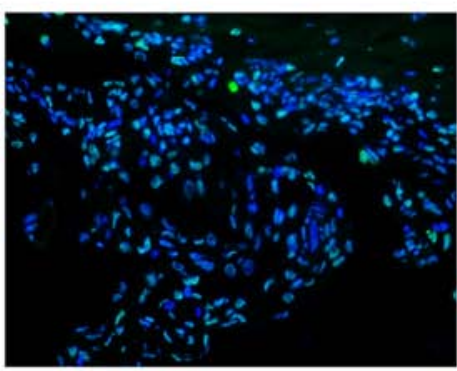

Paroxetine

Figure 4. Global DNA hydroxymethylation levels in the (A) hippocampus and (B) prefrontal cortex of the control, model, CaA and paroxetine treatment groups Global nuclear (blue) 5hmC levels (green) were examined using immunofluorescent staining with a 5hmC antibody. Magnification, x400. 5hmC, 5-hydroxymethylcytosine; CaA, caffeic acid.

in the nuclei of the cells, and was visualized as brown-colored staining (Fig. 2). As presented in Fig. 3, there was a significant difference in IOD value of $5 \mathrm{mC}$ between the model and control groups, and also between the paroxetine group and the model group $(\mathrm{P}<0.01$ and $\mathrm{P}<0.001$, respectively). Although the difference was not statistically significant, $5 \mathrm{mC}$ level was slightly lower in the CaA-treated group compared with the model group. However, in the prefrontal cortex, there was no significant difference in $5 \mathrm{mC}$ level among groups. Levels of $5 \mathrm{hmC}$ were confirmed by IF. The levels of $5 \mathrm{hmC}$ in the hippocampus were slightly increased in the CaA-treated group when compared with the model group. Notably, the levels of 5hmC increased in the paroxetine-treated group compared with the
Table II. Expression levels of 5hmC in the hippocampus in the control, model, $\mathrm{CaA}$ and paroxetine-treated groups analyzed using immunofluorescent staining.

\begin{tabular}{lcc}
\hline Group & Mean \pm SD & P-value \\
\hline Control & $0.0804 \pm 0.002$ & 0.18 \\
Model & $0.0664 \pm 0.009$ & $0.01^{\mathrm{a}}$ \\
CaA & $0.0823 \pm 0.002$ & 0.12 \\
Paroxetine & $0.0936 \pm 0.011$ & 0.01 \\
\hline
\end{tabular}

${ }^{\mathrm{a}} \mathrm{P}<0.05$ vs. paroxetine. $5 \mathrm{hmC}, 5$-hydroxymethylcytosine; $\mathrm{CaA}$, caffeic acid. 
A Hippocampus
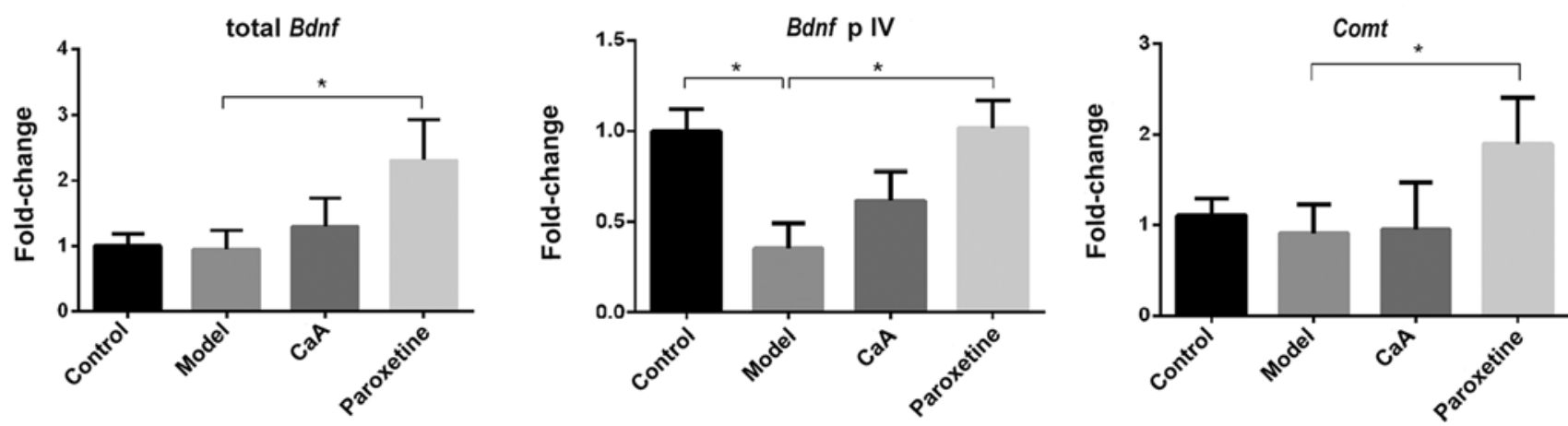

B Prefrontal cortex
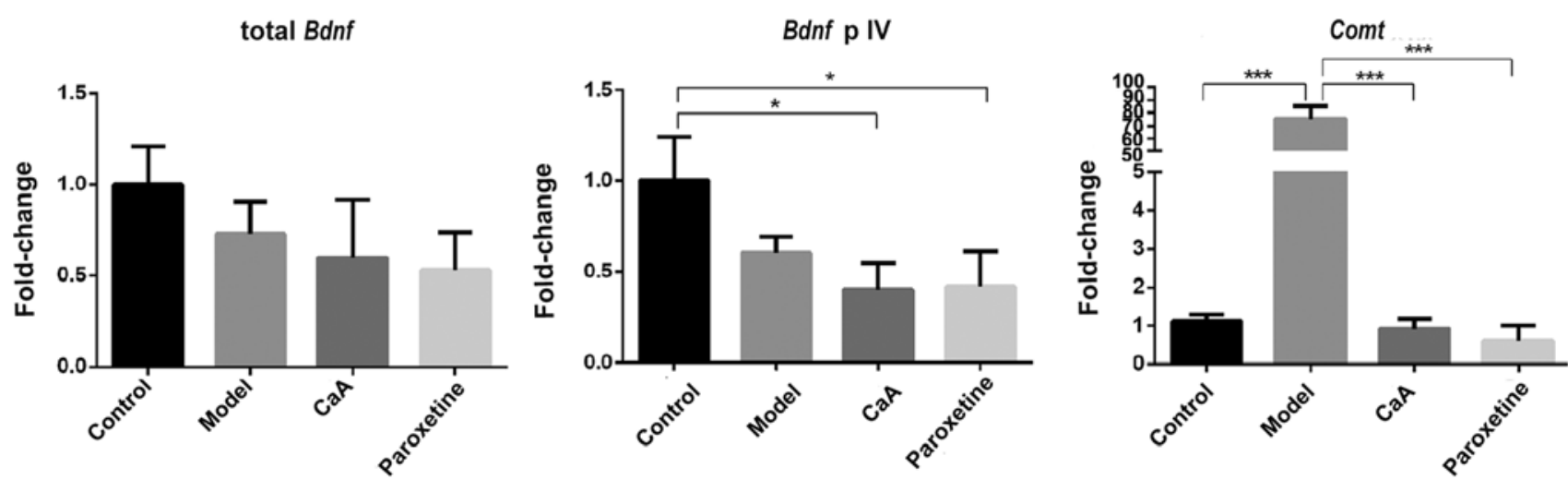

Figure 5. Gene expression levels of total Bdnf, Bdnf p IV and Comt in the (A) hippocampus and (B) prefrontal cortex of the control, model, CaA and paroxetine treatment groups. The mRNA levels were measured by reverse transcription-quantitative PCR. The experiment was repeated twice. Quantitative analyses were normalized to GAPDH. Results are expressed as a value relative to the control group using the $2^{-\Delta \Delta C q}$ method. ${ }^{*} \mathrm{P}<0.05$, ${ }^{* * *} \mathrm{P}<0.001$. Bdnf, brain-derived neurotropic factor; Comt, catechol-O-methyltransferase; p, promotor; CaA, caffeic acid.

model group in the hippocampus (Fig.4A; Table II). However, there was no difference in $5 \mathrm{hmC}$ levels in the prefrontal cortex when compared between all groups (Fig. 4B).

Effects of CaA on the expression of Bdnf and Comt. The present study assessed whether Bdnf and Comt expression could be affected by $\mathrm{CaA}$ and paroxetine, and whether these were associated with changes in the regulation of DNA methylation. In the hippocampus, levels of $B d n f$ promotor IV were decreased in the model group compared with the control group $(\mathrm{P}<0.05)$, and $\mathrm{CaA}$ caused a non-significant increase in Bdnf promotor IV levels. However, paroxetine treatment significantly reversed the inhibitory effects of CUMS. Total $B d n f$ and Comt levels were increased in the paroxetine-treated group compared with the model group (both $\mathrm{P}<0.05$ ), although there was no significant difference between the model group and the CaA-treated group. In the prefrontal cortex, there was no change in total Bdnf expression levels, but a significant difference was observed in the expression levels of the $B d n f$ promotor IV in $\mathrm{CaA}$ and paroxetine treatment groups vs. control. Notably, levels of Comt mRNA in the model group were significantly higher when compared with those in the control group $(\mathrm{P}<0.001)$; however, both $\mathrm{CaA}$ and paroxetine treatment significantly decreased Comt mRNA levels compared with the model group (both $\mathrm{P}<0.001$; Fig.5).

CaA influences the expression of methylated and hydroxymethylated genes. Dnmt1, Dnmt3a and Mecp2 serve important roles in the regulation of methylation, while the Tet1-3 family is involved in the regulation of hydroxymethylation $(28,29)$. Previous studies have demonstrated that aberrant epigenetic modification, such as DNA methylation and hydroxymethylation, is associated with psychiatric disorders, including depression $(30,31)$. In the present study, epigenetic-mediated gene expression was detected in the hippocampus and prefrontal cortex of rats. In the hippocampus, Dnmtl expression was increased in the model group when compared with the control group. CaA and paroxetine treatment blocked this increase but without statistical significance. Tetl expression was decreased in the model group $(\mathrm{P}<0.05)$ and paroxetine treatment could reverse this change. $\mathrm{MeCP} 2$ belongs to the family of methyl-CpG-binding domain proteins (MBDs), which bind to methylated DNA (32). In the present study, the expression of Mecp2 did not show any difference among groups. (Fig. 6A). There were no changes in the expression levels of Dnmtl, Dnmt3a or Tet1-3 genes in the prefrontal cortex; however, Mecp 2 levels were increased in the model, CaA and paroxetine-treated groups when compared with those in the control group (all $\mathrm{P}<0.05$; Fig. $6 \mathrm{~B}$ ).

$5 \mathrm{mC}$ and $5 \mathrm{hmC}$ enrichment in the promotor of Bdnf and Comt. In order to improve the current understanding of how changes in Bdnf and Comt gene expression may be associated with methylation levels, the present study predicted 5'-CpG island(s) in the promotor regions of both the Comt and Bdnf genes using online 


\section{A Hippocampus}
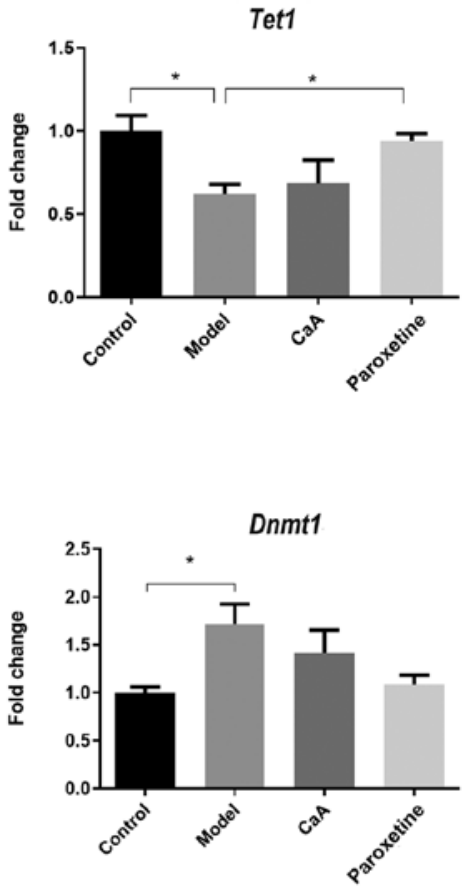

\section{B Prefrontal cortex}

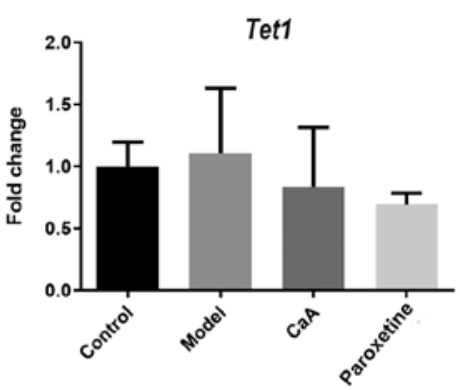

Dnmt1

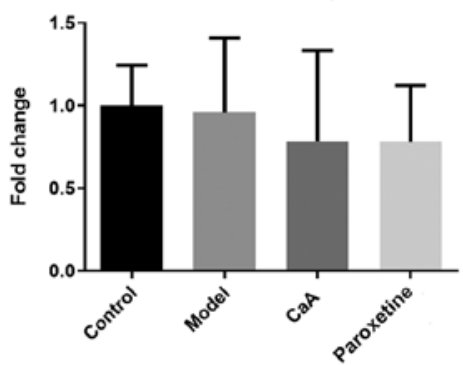

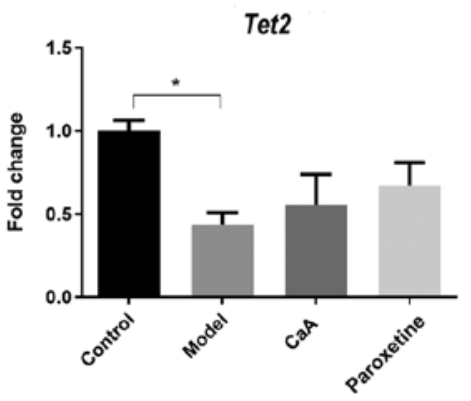
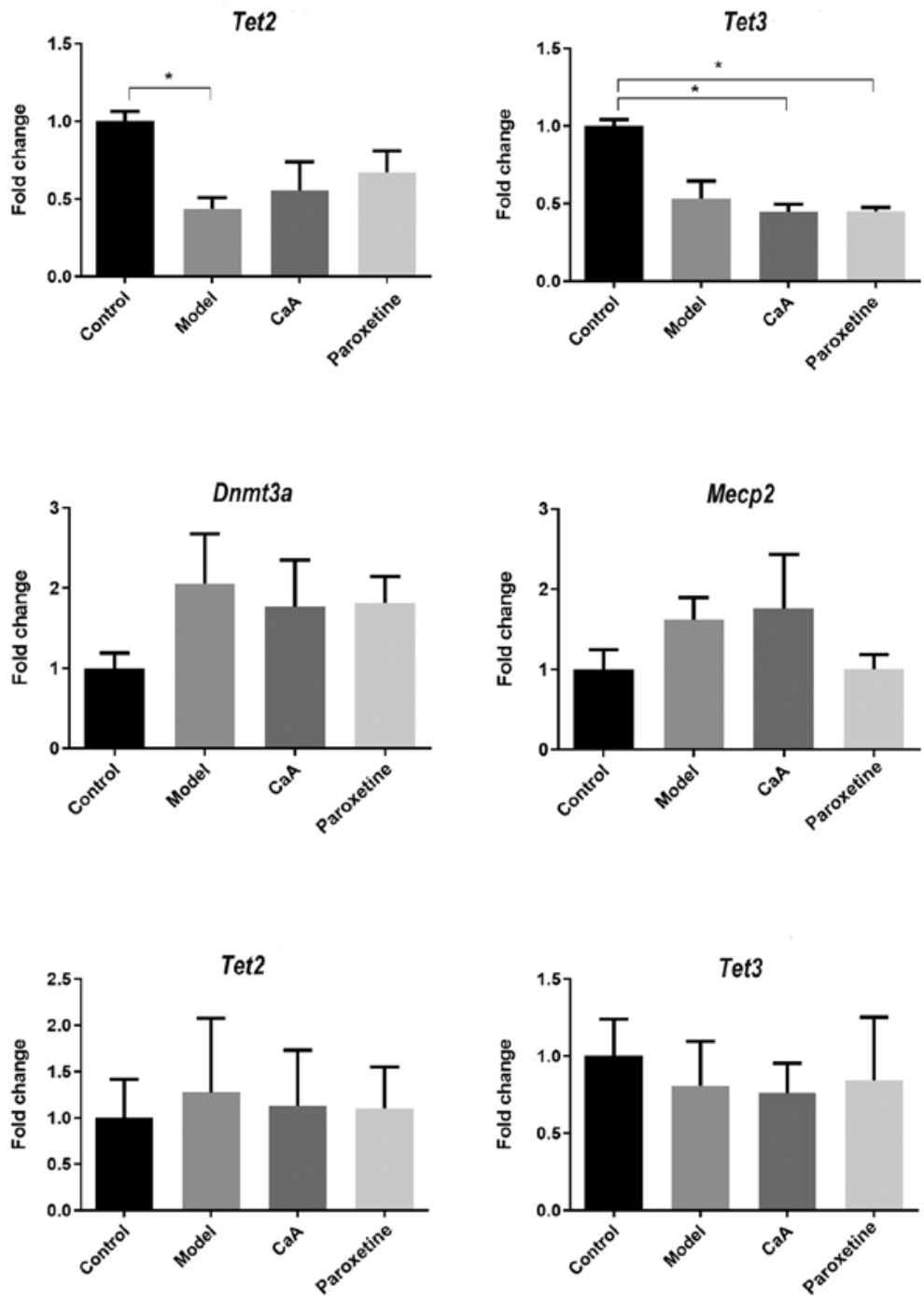

Dnmt3a
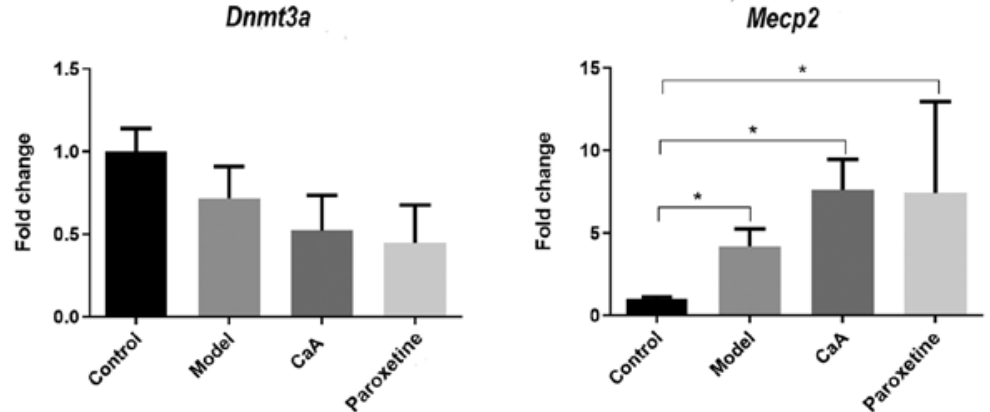

Figure 6. Tet1-3, Dnmt1, Dnmt3a and Mecp2 mRNA levels in the (A) hippocampus and (B) prefrontal cortex of the control, model, CaA and paroxetine treatment groups. ${ }^{*} \mathrm{P}<0.05$. Tet, Ten-eleven translocation; Dnmt, DNA methyltransferase; Mecp, methyl CpG binding protein; CaA, caffeic acid.

software (urogene.org/cgi-bin/methprimer/methprimer.cgi) (33) (Fig. S1). According to the position of the predicted 5'-CGI(s), the quantities of $5 \mathrm{mC}$ and $5 \mathrm{hmC}$ in these regions was determined using ChIP-qPCR. As presented in Fig. 7A, in the hippocampus, levels of $5 \mathrm{mC}$ were increased in the Bdnf and Comt promotors in the model group compared with the control. However, no changes were observed in the $\mathrm{CaA}$ and paroxetine-treated group. The expression levels of $5 \mathrm{mC}$ were significantly decreased in the Comt promotor of the prefrontal cortex model compared with those in the control group $(\mathrm{P}<0.05$; Fig. 7B). Neither of the two promotors showed any changes with respect to $5 \mathrm{hmC}$ levels. There was an increase of $5 \mathrm{mC} / 5 \mathrm{hmC}$ in the $B d n f$ and Comt gene promotors in the model group compared with the control group in the hippocampus. $\mathrm{CaA}$ treatment may adjust the balance of $5 \mathrm{mC} / 5 \mathrm{hmC}$ in the hippocampus. There was a decrease of $5 \mathrm{mC} / 5 \mathrm{hmC}$ in the Comt 


\section{A Hippocampus}
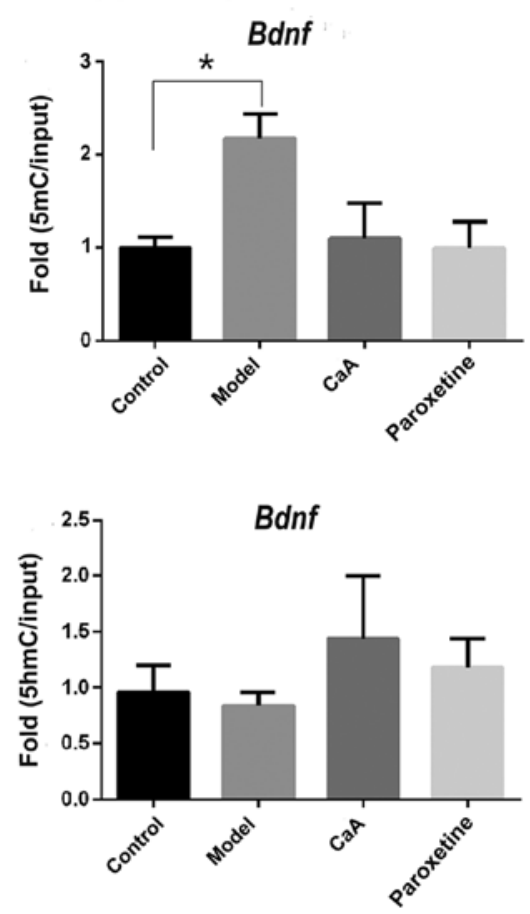

\section{B Prefrontal cortex}
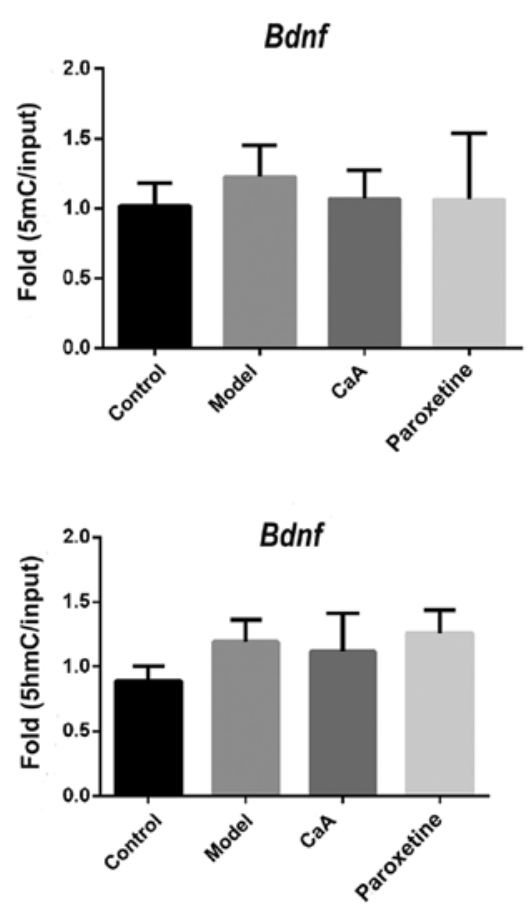
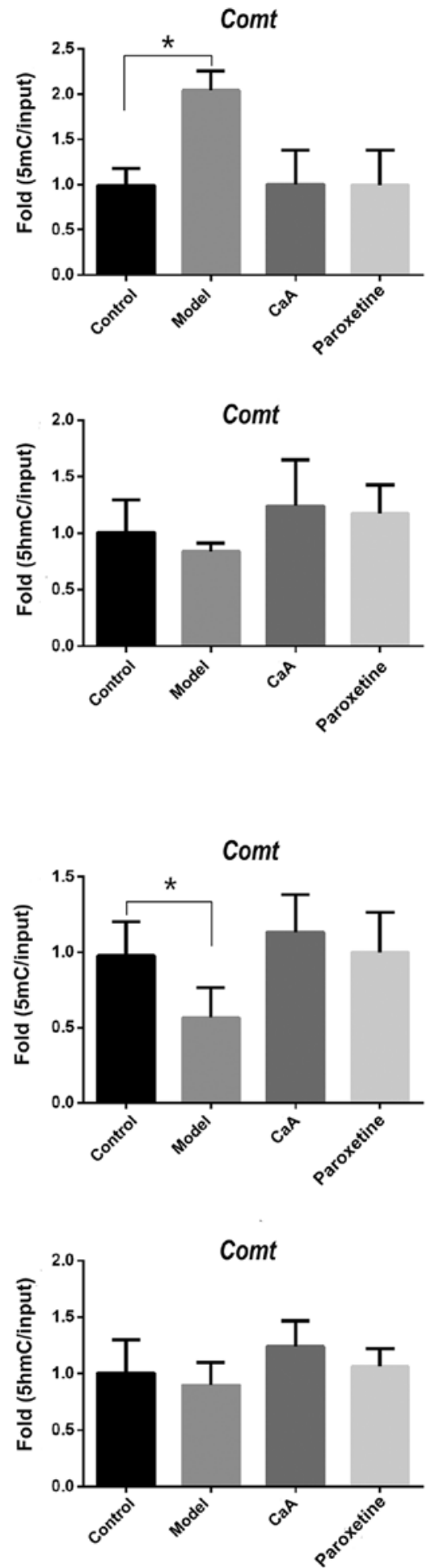

Figure 7. Enrichment of $5 \mathrm{mC}$ and $5 \mathrm{hmC}$ was measured at the Bdnf and Comt promotor regions in the (A) hippocampus and (B) prefrontal cortex. Data were normalized by input and then compared with the control. ${ }^{*} \mathrm{P}<0.05$. Bdnf, brain-derived neurotropic factor; Comt, catechol-O-methyltransferase; $5 \mathrm{mC}, 5$-methylcytosine; 5hmC, 5-hydroxymethylcytosine; CaA, caffeic acid.

gene promotor in the model group vs. the control group in the prefrontal cortex, which may be restored by CaA.

\section{Discussion}

The results of the present study may provide novel insight into genetic in depression, and demonstrated that epigenetic changes for this illness are likely to involve multiple genes. Extensive studies have indicated that epigenetic modifications, such as histone acetylation and DNA methylation, serve a crucial role in the modification of DNA during neuronal gene expression and memory formation $(34,35)$. In addition, levels of $5 \mathrm{hmC}$ are most abundant in the brain, which is controlled by the activation of gene transcription $(36,37)$. In the present 
study, it was hypothesized that the antidepressant-like properties of CaA may partially involve changes at the DNA methylation and hydroxymethylation levels.

In the present study, the CUMS model was selected for investigation, which is regarded as one of the most valid and reliable animal models $(24,25)$. Behavioral data showed that $\mathrm{CaA}$ exerted a slight antidepressant-like effect. In the analysis of global methylation status, no robust evidence of widespread methylation differences was observed between the control and $\mathrm{CaA}$ groups. However, non-significant trends towards lower DNA methylation levels in the CaA group were observed. Furthermore, in the hippocampus, Dnmtl and Dnmt3a mRNA levels in the model group were increased compared with those in the control, and $\mathrm{CaA}$ treatment may lower this trend but this was not significant. Tetl and Tet 2 mRNA levels were decreased in the model group compared with those in the control, and this was reversed in the $\mathrm{CaA}$ group. The expression levels of Dnmt1/Dnmt3a and Tet1/Tet2 were associated with the levels of global DNA methylation and hydroxymethylation, respectively, which were consistent with the results of the $5 \mathrm{mC}$ IHC and $5 \mathrm{hmC}$ IF expression analysis in the hippocampus. A previous epigenetic study has indicated potential associations between epigenetic patterns and abnormalities in the hippocampus, which is vulnerable to the pathogenesis of MDD (38). No obvious changes in global $5 \mathrm{mC}$ and $5 \mathrm{hmC}$ levels were observed in the prefrontal cortex following $\mathrm{CaA}$ treatment. The present study revealed that $B d n f$ and Comt genes had differential expression patterns in the hippocampus and prefrontal cortex, respectively. Specifically, the model group showed decreased $B d n f$ mRNA levels, which were restored to within the normal range in the hippocampus following $\mathrm{CaA}$ and paroxetine treatment. These results are consistent with previous human patient and animal model studies demonstrating that BDNF deficiency, particularly those lacking promotor IV-driven $B d n f$ transcription, underlies depressive states, and that antidepressant treatments restore this expression in the hippocampus $(39,40)$. Preclinical studies have established that hippocampal BDNF expression serves a critical role in the etiology of depression; however, the exact underlying molecular mechanisms of this role remain unclear. Notably, the complex regulation of $B d n f$ gene transcription may provide the opportunity to clarify this uncertainty. Keller et al (40) first reported that lower Bdnf expression is associated with increased DNA methylation of $B d n f$ promotor IV. Therefore, the present study analyzed the levels of $5 \mathrm{mC}$ and $5 \mathrm{hmC}$ in the promotor region of the $B d n f$ gene following $\mathrm{CaA}$ treatment in rats. It was demonstrated that increased Dnmtl levels in the model group were associated with increased levels of $5 \mathrm{mC}$ in the $B d n f$ gene promotor. There was a decrease in $5 \mathrm{hmC}$ levels in the model group compared with the control group; however, this was not statistically significant. When these findings were expressed as a ratio of $5 \mathrm{mC} / 5 \mathrm{hmC}$, the data showed a statistically significant increase in the $B d n f$ promotor. These data suggested a shift in the equilibrium towards methylation in the hippocampus following CUMS, which may have been driven by the increased quantity of steady state $5 \mathrm{mC}$ in the promotor regions. CaA treatment may restore the expression of $B d n f$ by adjusting the balance of $5 \mathrm{mC} / 5 \mathrm{hmC}$ in the hippocampus. Notably, there was a marked increase in Comt gene expression in the prefrontal cortex in the model group compared with the control group, and $\mathrm{CaA}$ reversed this.
There was also a decrease of $5 \mathrm{mC} / 5 \mathrm{hmC}$, which was shifted towards hydroxymethylation in the prefrontal cortex. These findings indicate that the expression of Comt gene can be regulated by DNA methylation and hydroxymethylation in the brain. COMT is the primary regulator of dopamine clearance in extra-striatal regions of the brain, including the prefrontal cortex $(13,41)$. Elevated levels of COMT may accelerate the metabolism of dopamine and result in decreased dopamine levels, which may in turn influence brain function, potentially leading to depression. Of note, $\mathrm{CaA}$ treatment resulted in differential DNA methylation regulation of Bdnf and Comt genes in the hippocampus and the prefrontal cortex, respectively. During antidepressant treatment, epigenetic mechanisms may exert a dynamic and tissue-specific regulation of gene transcription (42). Therefore, studies investigating epigenetic mechanisms have improved the current understanding of the molecular basis for antidepressant treatment in MDD.

In the present study, the effects of $\mathrm{CaA}$ on MDD had, in part, the same trend as the antidepressant, paroxetine. It was revealed that there were epigenetic changes in the genes $(B d n f$ and $\operatorname{Com} t$ ) associated with depression, which were reversible with $\mathrm{CaA}$ treatment. It has previously been demonstrated that $\mathrm{CaA}$ could enhance the expression of microRNA (miR)-148a by decreasing Dnmt1 mRNA levels (43). There is also a support that $\mathrm{CaA}$ may act as a histone deacetylase inhibitor for breast cancer treatment (44). Thus, $\mathrm{CaA}$, as a phytochemical and a dietary supplement, may be a comprehensive epigenetic modulator, and may have potential as an antidepressant. The results of the present study are promising and these trends require further validation in studies with larger sample size. However, it should be noted that the present study did not detect the effects of every epigenetic-associated enzyme on gene transcription, such as DNMTs/MBDs mediating DNA methylation and histone deacetylases/histone acetyltransferases. It is hypothesized that $\mathrm{CaA}$ may recruit the binding of the aforementioned enzymes to specific $\mathrm{CpG}$ sites of the gene promotor. These putative bulky enzymatic complexes may inhibit the binding of transcription co-activators at the promotor leading to decreased gene expression, and vice versa. Future mechanistic studies should aim to elucidate the mechanisms of $\mathrm{CaA}$ as a direct or indirect epigenetic modulator. Further experiments should also investigate the effects of different $\mathrm{CaA}$ dosages and administration methods.

In conclusion, the present results demonstrated that there were epigenetic changes in the hippocampus and prefrontal cortex in rats with CUMS. CaA may function as a modulator of DNA methylation to regulate Bdnf and Comt gene transcription. Although a limitation of the present study was a lack of statistical power, the trends observed provide a mechanistic basis for the use of this phytochemical agent in the treatment of depression.

\section{Acknowledgements}

Not applicable.

\section{Funding}

The present study was funded by The National Natural Science Foundation of China (grant nos. 81903365, 81673228 
and 81473020), The Natural Science Foundation of Jiangsu Province (grant no. BK20161571) and The Natural Science Foundation of the Higher Education Institution of Jiangsu Province (grant no. 16KJA330002).

\section{Availability of data and materials}

The datasets used and/or analyzed during the current study are available from the corresponding author on reasonable request.

\section{Authors' contributions}

QW and LL conceived and designed the experiments. JH, SC, DW and LW performed the experiments. QW, ZZ and SC analyzed data. QW wrote the manuscript. All the authors read and approved the final manuscript.

\section{Ethics approval and consent to participate}

The present study was approved by The Nanjing Medical University Institutional Animal Care and Use Committee (Nanjing, China) (approval no. NJMU2015/81473020).

\section{Patient consent for publication}

Not applicable.

\section{Competing interests}

The authors declare that they have no competing interests.

\section{References}

1. Touaibia M, Jean-François $\mathrm{J}$ and Doiron J: Caffeic Acid, a versatile pharmacophore: An overview. Mini Rev Med Chem 11: 695-713, 2011.

2. Onori P, DeMorrow S, Gaudio E, Franchitto A, Mancinelli R, Venter J, Kopriva S, Ueno Y, Alvaro D, Savage J, et al: Caffeic acid phenethyl ester decreases cholangiocarcinoma growth by inhibition of NF-kappaB and induction of apoptosis. Int J Cancer 125: 565-576, 2009.

3. Son $\mathrm{S}$ and Lewis BA: Free radical scavenging and antioxidative activity of caffeic acid amide and ester analogues: Structure-activity relationship. J Agric Food Chem 50: 468-472, 2002.

4. Koltuksuz U, Mutuş HM, Kutlu R, Ozyurt H, Cetin S, Karaman A, Gürbüz N, Akyol O and Aydin NE: Effects of caffeic acid phenethyl ester and epidermal growth factor on the development of caustic esophageal stricture in rats. J Pediat Surg 36: 1504-1509, 2001.

5. Borrelli F, Izzo AA, Di Carlo G, Maffia P, Russo A, Maiello FM, Capasso F and Mascolo N: Effect of a propolis extract and caffeic acid phenethyl ester on formation of aberrant crypt foci and tumors in the rat colon. Fitoterapia 73 (Suppl 1): S38-S43, 2002 .

6. Lee WJ and Zhu BT: Inhibition of DNA methylation by caffeic acid and chlorogenic acid, two common catechol-containing coffee polyphenols. Carcinogenesis 27: 269-277, 2006.

7. Ira E, Zanoni M, Ruggeri M, Dazzan P and Tosato S: COMT, neuropsychological function and brain structure in schizophrenia: A systematic review and neurobiological interpretation. J Psychiatry Neurosci 38: 366-380, 2013.

8. Samavat $\mathrm{H}$ and Kurzer MS: Estrogen metabolism and breast cancer. Cancer Lett 356A: A231-A243, 2015.

9. Matsumoto M, Weickert CS, Beltaifa S, Kolachana B, Chen J, Hyde TM, Herman MM, Weinberger DR and Kleinman JE: Catechol O-methyltransferase (COMT) mRNA expression in the dorsolateral prefrontal cortex of patients with schizophrenia. Neuropsychopharmacology 28: 1521-1530, 2003
10. Lin CH, Chaudhuri KR, Fan JY, Ko CI, Rizos A, Chang CW, Lin HI and Wu YR: Depression and Catechol-O-methyltransferase (COMT) genetic variants are associated with pain in Parkinson's disease. Sci Rep 7: 6306, 2017.

11. Egan MF, Goldberg TE, Kolachana BS, Callicott JH, Mazzanti CM, Straub RE, Goldman D and Weinberger DR: Effect of COMT Val ${ }^{108 / 158}$ Met genotype on frontal lobe function and risk for schizophrenia. Proc Natl Acad Sci USA 98: 6917-6922, 2001

12. Swift-Scanlan T, Smith CT, Bardowell SA and Boettiger CA: Comprehensive interrogation of $\mathrm{CpG}$ island methylation in the gene encoding COMT, a key estrogen and catecholamine regulator. BMC Med Genomics 7: 5, 2014.

13. Na KS, Won E, Kang J, Kim A, Choi S, Tae WS, Kim YK, Lee MS, Joe SH and Ham BJ: Differential effect of COMT gene methylation on the prefrontal connectivity in subjects with depression versus healthy subjects. Neuropharmacology 137 : 59-70, 2018.

14. Wu Q, Odwin-Dacosta S, Cao S, Yager JD and Tang WY: Estrogen down regulates COMT transcription via promoter DNA methylation in human breast cancer cells. Toxicol Appl Pharmacol 367: 12-22, 2019.

15. Bustamante AC, Armstrong DL and Uddin M: Epigenetic profiles associated with major depression in the human brain. Psychiatry Res 260: 439-442, 2018

16. Tahiliani M, Koh KP, Shen Y, Pastor WA, Bandukwala H, Brudno Y, Agarwal S, Iyer LM, Liu DR, Aravind L, et al: Conversion of 5-methylcytosine to 5-hydroxymethylcytosine in mammalian DNA by MLL partner TET1. Science 324: 930-935, 2009.

17. Ito S, D'Alessio AC, Taranova OV, Hong K, Sowers LC and Zhang Y: Role of Tet proteins in $5 \mathrm{mC}$ to $5 \mathrm{hmC}$ conversion, ES-cell self-renewal and inner cell mass specification. Nature 466: 1129-1133, 2010.

18. Wei Y, Melas PA, Wegener G, Mathé AA and Lavebratt C: Antidepressant-like effect of sodium butyrate is associated with an increase in TET1 and in 5-hydroxymethylation levels in the Bdnf gene. Int J Neuropsychopharmacol 18: pyu032, 2014.

19. Angelucci F, Brenè S and Mathé AA: BDNF in schizophrenia, depression and corresponding animal models. Mol Psychiatry 10: 345-352, 2005

20. Aid T, Kazantseva A, Piirsoo M, Palm K and Timmusk T: Mouse and rat BDNF gene structure and expression revisited. J Neurosci Res 85: 525-535, 2007.

21. Lubin FD, Roth TL and Sweatt JD: Epigenetic regulation of BDNF gene transcription in the consolidation of fear memory. J Neurosci 28: 10576-10586, 2008.

22. Boulle F, van den Hove DL, Jakob SB, Rutten BP, Hamon M, van Os J, Lesch KP, Lanfumey L, Steinbusch HW and Kenis G: Epigenetic regulation of the BDNF gene: Implications for psychiatric disorders. Mol Psychiatry 17: 584-596, 2012.

23. Martinowich K, Hattori D, Wu H, Fouse S, He F, Hu Y, Fan G and Sun YE: DNA methylation-related chromatin remodeling in activity-dependent BDNF gene regulation. Science 302: 890-893, 2003.

24. Hill MN, Hellemans KG, Verma P, Gorzalka BB and Weinberg J: Neurobiology of chronic mild stress: Parallels to major depression. Neurosci Biobehav Rev 36: 2085-2117, 2012.

25. Willner P: Validity, reliability and utility of the chronic mild stress model of depression: A 10-year review and evaluation. Psychopharmacology (Berl) 134: 319-329, 1997.

26. Yu X, Qiao S, Wang D, Dai J, Wang J, Zhang R, Wang L and Li L: A metabolomics-based approach for ranking the depressive level in a chronic unpredictable mild stress rat model. Rsc Adv. 6: 25751-25765, 2016.

27. Livak KJ and Schmittgen TD: Analysis of relative gene expression data using real-time quantitative PCR and the 2(-Delta Delta C(T)) Method. Methods 25: 402-408, 2001.

28. Jeschke J, Collignon E and Fuks F: Portraits of TET-mediated DNA hydroxymethylation in cancer. Curr Opin Genet Dev 36: 16-26, 2016.

29. Rivas MP, Aguiar TFM, Fernandes GR, Caires-Júnior LC, Goulart E, Telles-Silva KA, Cypriano M, de Toledo SRC, Rosenberg C, Carraro DM, et al: TET Upregulation Leads to 5-Hydroxymethylation Enrichment in Hepatoblastoma. Front Genet 10: 553, 2019.

30. Irwin RE, Pentieva K, Cassidy T, Lees-Murdock DJ, McLaughlin M, Prasad G, McNulty H and Walsh CP: The interplay between DNA methylation, folate and neurocognitive development. Epigenomics 8: 863-879, 2016. 
31. Gross JA, Pacis A, Chen GG, Drupals M, Lutz PE, Barreiro LB and Turecki G: Gene-body 5-hydroxymethylation is associated with gene expression changes in the prefrontal cortex of depressed individuals. Transl Psychiatry 7: e1119, 2017.

32. Nan X, Campoy FJ and Bird A: MeCP2 is a transcriptional repressor with abundant binding sites in genomic chromatin. Cell 88: 471-481, 1997.

33. Li LC and Dahiya R: MethPrimer: Designing primers for methylation PCRs. Bioinformatics 18: 1427-1431, 2002.

34. Seo MK, Ly NN, Lee CH, Cho HY, Choi CM, Nhu LH, Lee JG, Lee BJ, Kim GM, Yoon BJ, et al: Early life stress increases stress vulnerability through BDNF gene epigenetic changes in the rat hippocampus. Neuropharmacology 105: 388-397, 2016.

35. Brenet F, Moh M, Funk P, Feierstein E, Viale AJ, Socci ND and Scandura JM: DNA methylation of the first exon is tightly linked to transcriptional silencing. PLoS One 6: e14524, 2011.

36. Klengel T, Pape J, Binder EB and Mehta D: The role of DNA methylation in stress-related psychiatric disorders. Neuropharmacology 80: 115-132, 2014.

37. Li W and Liu M: Distribution of 5-hydroxymethylcytosine in different human tissues. J Nucleic Acids 2011: 870726, 2011

38. Na KS, Chang HS, Won E, Han KM, Choi S, Tae WS, Yoon HK, Kim YK, Joe SH, Jung IK, et al: Association between glucocorticoid receptor methylation and hippocampal subfields in major depressive disorder. PLoS One 9: e85425, 2014.

39. Sakata K, Jin L and Jha S: Lack of promoter IV-driven BDNF transcription results in depression-like behavior. Genes Brain Behav 9: 712-721, 2010
40. Keller S, Sarchiapone M,Zarrilli F, Videtic A, Ferraro A, Carli V, Sacchetti S, Lembo F, Angiolillo A, Jovanovic N, et al: Increased BDNF promoter methylation in the Wernicke area of suicide subjects. Arch Gen Psychiatry 67: 258-267, 2010.

41. Laatikainen LM, Sharp T, Harrison PJ and Tunbridge EM: Sexually dimorphic effects of catechol-O-methyltransferase (COMT) inhibition on dopamine metabolism in multiple brain regions. PLoS One 8: e61839, 2013.

42. Kim JK, Samaranayake M and Pradhan S: Epigenetic mechanisms in mammals. Cell Mol Life Sci 66: 596-612, 2009.

43. Li Y, Jiang F, Chen L, Yang Y, Cao S, Ye Y, Wang X, Mu J, Li Z and $\mathrm{Li}$ L: Blockage of TGF $\beta$-SMAD2 by demethylation-activated miR-148a is involved in caffeic acid-induced inhibition of cancer stem cell-like properties in vitro and in vivo. FEBS Open Bio 5: 466-475, 2015.

44. Omene C, Kalac M, Wu J, Marchi E, Frenkel K and O'Connor OA: Propolis and its Active Component, Caffeic Acid Phenethyl Ester (CAPE), Modulate Breast Cancer Therapeutic Targets via an Epigenetically Mediated Mechanism of Action. J Cancer Sci Ther 5: 334-342, 2013.

(i) (3) This work is licensed under a Creative Common Attribution-NonCommercial-NoDerivatives 4.0 International (CC BY-NC-ND 4.0) License. 